\title{
Socioecological influences on the dispersal of female mountain gorillas - evidence of a second folivore paradox
}

\author{
Andrew M. Robbins • Tara S. Stoinski • \\ Katie A. Fawcett $\cdot$ Martha M. Robbins
}

Received: 18 March 2008 /Revised: 20 September 2008/Accepted: 8 November 2008 / Published online: 16 December 2008

(C) The Author(s) 2008. This article is published with open access at Springerlink.com

\begin{abstract}
Socioecological models indicate that the group structure and female dispersal patterns of primates are determined primarily by the abundance and distribution of food, predation pressures, and infanticide risks. In response to those influences, females of folivorous primates are considered relatively free to disperse into groups with the optimal size and structure. Yet some folivores live in small groups despite a potentially higher risk of predation, an apparent inconsistency known as the folivore paradox. This paper examines the female dispersal of a folivorous primate, the Virunga mountain gorillas. Mountain gorillas currently have no natural predators, but this species presents a different version of the folivore paradox: why do $50-60 \%$ of females reside in smaller one-male groups despite a higher risk of infanticide? In this study, females left one-male groups more frequently than multimale groups, but transfer destinations were not consistently biased toward multimale groups and those groups did not have higher immigration rates. We found no evidence of dispersal to avoid feeding competition within large groups, even as they have become three to five times larger than average. Thus, the lack of a consistent bias toward multi-
\end{abstract}

Communicated by D. Watts

A. M. Robbins $(\square) \cdot$ M. M. Robbins

Max Planck Institute for Evolutionary Anthropology,

Deutscher Platz 6,

04103 Leipzig, Germany

e-mail: robbins@eva.mpg.de

T. S. Stoinski $\cdot$ K. A. Fawcett

Dian Fossey Gorilla Fund International,

800 Cherokee Ave SE,

Atlanta, GA 30315-1440, USA male groups was not because they are typically larger than one-male groups. Instead, the apparent inconsistencies may reflect limited female transfer opportunities, other influences on dispersal, and possibly an evolutionary disequilibrium in which current behavior does not optimize fitness.

Keywords Gorillas · Dispersal · Folivore paradox ·

Socioecological model $\cdot$ Infanticide · Predation .

Feeding competition

\section{Introduction}

Socioecological models indicate that the group size and female dispersal patterns of primates are determined primarily by the abundance and distribution of food (Wrangham 1980; Isbell 1991), predation pressures (van Schaik 1989), and infanticide risks (Sterck et al. 1997). When such food is clumped into patches that are small enough to be monopolized by a fraction of the group, within-group contest competition is expected, leading to nepotistic female dominance relationships (Wrangham 1980; van Schaik 1989). Females cannot disperse to other groups without losing valuable alliances, so group size is relatively difficult to control (Sterck et al. 1997). When limiting food resources are highly dispersed, within-group scramble competition is expected. Dominance hierarchies may be weak or nonexistent, and females can disperse relatively freely to adjust group size (ibid). Within-group contest competition is often associated with clumped fruit, and foliage is often associated with within-group scramble competition, though such generalizations are not without exceptions (e.g., Koenig et al. 1998).

Larger groups are expected to have lower costs of predation due to better detection of predators (Hill and Lee 1998; Rogovin et al. 2004; but also see Hebblewhite 
and Pletscher 2002). Nonetheless, some folivores live in groups that are considered smaller than necessary to avoid within-group scramble competition, despite a substantial risk of predation (Janson and Goldsmith 1995). This apparent inconsistency has been known as the "folivore paradox" (Steenbeek and van Schaik 2001), and we will call it the "original" folivore paradox.

The risk of infanticide is proposed to peak at an intermediate group size due to the number of males in the group. When groups contain only one male, larger numbers of females may attract greater aggression, takeovers, and infanticide by outsider males (Isbell 1991; Struhsaker and Leland 1988). But as the number of females in a group increases, the probability also increases that more than one of them will be in estrus at the same time. At those times, it may become harder for the dominant male to monopolize reproduction, so subordinates have greater incentive to remain (Alberts et al. 2003; Altmann 1962). Thus, larger groups of females are more likely to be multimale (Lindenfors et al. 2004). Multimale groups can provide better protection against infanticide (Janson and van Schaik 2000), so the effect of group size on infanticide may reach a turning point when its females cannot be monopolized by a single male (Crockett and Janson 2000; Chapman and Pavelka 2005).

The group size of some species may be limited by the costs of infanticide more than within-group scramble competition (Fig. 1a). If a species had the optimal group size shown in Fig. 1a, but researchers did not recognize the costs of infanticide, then they might question why those groups were not larger (because larger groups could have lower predation costs without much increase in scramble competition). Such questioning would represent the original folivore paradox, and Fig. 1a illustrates how infanticide costs may provide the answer for resolving that paradox (Crockett and Janson 2000).

In Fig. 1a, the optimal size occurs where groups are primarily one male, as indicated by the increase in infanticide costs as those groups get larger. In other species, the optimal size may occur where infanticide costs are decreasing, as larger groups become more likely to be multimale (Fig. 1b). Infanticide can become a driving force for larger groups even if predation costs are minimal, but group size may be limited by within-group scramble competition. If species were below the optimal group size in Fig. 1b, even after researchers recognized the costs of predation, infanticide, and within-group scramble competition, then it would represent a "second" folivore paradox.

Both folivore paradoxes ask why group sizes are not larger when within-group scramble competition is relatively low. But whereas infanticide may be the limiting factor that resolves the original folivore paradox, the answer to the second paradox has not been determined. Both cases may
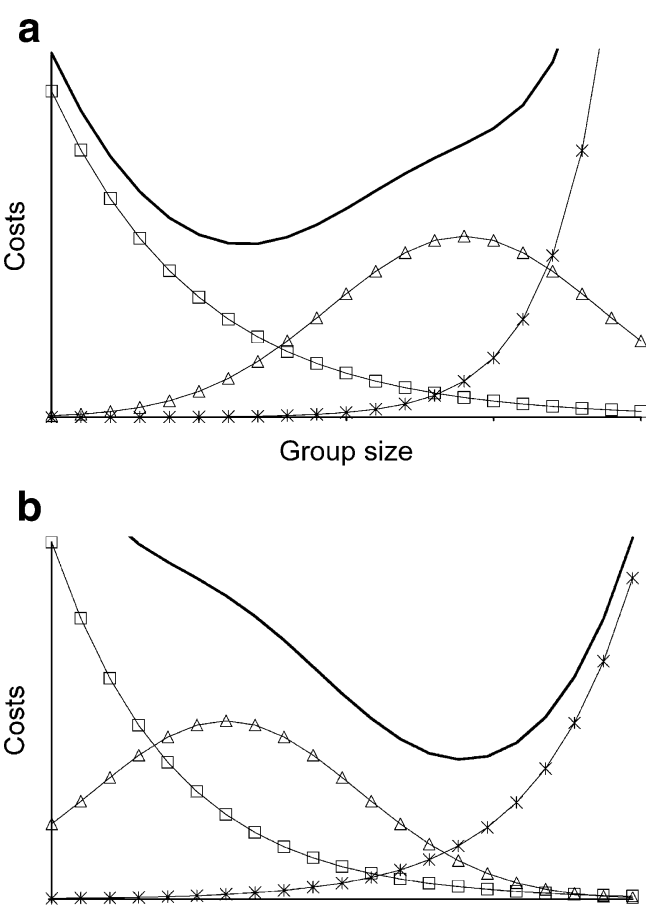

Group size

Fig. 1 Reproductive costs versus group size. Costs of predation (squares), infanticide (triangles), and feeding competition (asterisks). The optimal group size occurs when the total cost (dark solid line) is minimized. The total cost equals the sum of the other three costs, plus a small fixed cost (independent of group size) is added for purposes of clarity (i.e., so the lines do not overlap). a Proposed solution to the original folivore paradox because group size is limited by infanticide risk before feeding competition. b Potential scenario for a second folivore paradox, if observed group sizes are smaller than optimum, leading to extra infanticide risks even while feeding competition remains minimal. Adapted from Crockett and Janson (2000) and Chapman and Pavelka (2005)

still be difficult to recognize and even harder to confirm because researchers have not fully quantified how group size affects the costs of predation, infanticide, and withingroup scramble competition (Sterck et al. 1997; Isbell and Young 2002; Koenig 2002).

This paper examines the socioecological influences on the dispersal of female mountain gorillas in the Virunga Volcano region from 1967 to 2005, using the long-term demographic databases of the Dian Fossey Gorilla Fund International and the International Gorilla Conservation Program. Mountain gorillas feed on abundant evenly distributed foliage, so females should be able to disperse relatively freely to maintain the optimal group size. Both natal and secondary dispersal are common for female mountain gorillas, who transfer directly from one group to another, whereas adult males (silverbacks) become solitary and attempt to establish their own group (Harcourt et al. 1976). Natal dispersal is generally attributed to inbreeding avoidance (e.g., Clutton-Brock 1989; Pusey and Wolf 1996; Harcourt 1978; Watts 1990a), although a concurrent study 
found little evidence to support such expectations (unpublished data). Regardless, inbreeding avoidance cannot explain most cases of secondary dispersal (Stewart and Harcourt 1987) or most destinations for either type of transfer, which are the focus of this paper.

Initial studies of this population found that transferring females preferred smaller newly formed groups and lone silverbacks, which has been attributed to feeding competition (Harcourt 1978; Harcourt et al. 1981). Since then, the study groups have become three to five times larger than average, so this study should provide the clearest evidence of any effect from group size. However, no decline in female reproductive success was observed in those very large groups, thus providing no indication that group size is constrained by within-group scramble competition (Robbins et al. 2007). For example, group size accounted for less than $0.1 \%$ of the variance in the average interbirth intervals of 39 females $(p=0.87$, ibid).

Leopards were reportedly killing mountain gorillas as recently as the 1960s, but those predators have subsequently been extirpated from the region (Schaller 1963). Humans have hunted gorillas for more than a century and possibly even millennia, for trophies and occasionally for bushmeat (Weber and Vedder 1983; Plumtpre and Williamson 2001; Harcourt and Stewart 2007). It has been argued that the main female counterstrategy against such predation is to associate with a male who has longer canines and is typically twice her size (Harcourt and Stewart 2007). Females might also benefit from improved detection of predators by forming larger groups (as predicted by the socioecological models), but conversely it might become harder for each of them to maintain proximity to their protector (e.g., competition for proximity is described in Watts 1994a). Unfortunately, there is insufficient information to show whether predation costs have been lower in larger groups, so although within-group scramble competition seems minimal, it is unclear whether the original folivore paradox applies to this population.

Regardless of whether the original folivore paradox applies to mountain gorillas, they are still an interesting species for examining the socioecological influences on female dispersal because both one-male and multimale groups can be observed in the same population (median= $40 \%$ multimale groups, range $=8-53 \%, \mathrm{~N}=6$ censuses of the entire population; Kalpers et al. 2003). Infant mortality has been nearly twice as high in one-male groups, a significant difference that is at least partly due to infanticide (Fossey 1984; Watts 1989; Robbins et al. 2007). For example, infanticide typically occurs when the silverback dies in one-male groups but not when the dominant male dies in multimale groups (ibid). Known cases of infanticide have claimed the lives of $10.4 \%$ of offspring born in onemale groups, which is significantly higher than $1.5 \%$ for offspring born in multimale groups (Fisher test, $p=0.015$, unpublished details from Robbins et al. 2007). Infanticide protection has been considered as the main reason why gorillas form groups at all (Harcourt and Greenberg 2001; Harcourt and Stewart 2007).

Although within-group scramble competition seems minimal, and the risk of infanticide is higher in one-male groups, census data have shown that $50-60 \%$ of adult females are typically in one-male groups (Weber and Vedder 1983; Sholley 1989). Thus, mountain gorillas may represent an example of the second folivore paradox: if females are not constrained by within-group scramble competition, then why are not more of them in large multimale groups where the risk of infanticide is lower? We examine three potential explanations.

Firstly, researchers may not have adequately quantified how group size is constrained by within-group scramble competition. If the costs of dispersal are small, then females may leave groups as soon as within-group scramble competition begins to reduce their fitness (Gillespie and Chapman 2001; Dias and Strier 2003). If so, then studies of dispersal may provide a more sensitive measure of withingroup scramble competition than previous studies of female reproductive success (Watts 1990a, 1996; Robbins et al. 2007). This population has shown other evidence of withingroup scramble competition, such as longer feeding times in larger groups, but such increases were considered to be very small (Watts 1988, 1998). Evidence for within-group scramble competition among folivorous primates has often not involved direct measures of female fertility (Janson and Goldsmith 1995; Snaith and Chapman 2007).

Secondly, females may sometimes lack opportunities to join a multimale group. Female mountain gorillas usually do not disperse while lactating or pregnant, again due to the risk of infanticide (but see Sicotte 2000). So even if they always joined a multimale group before giving birth, they could end up in a one-male group temporarily, if a silverback died or emigrated, or if the group fissioned. Even after weaning an offspring, females have an average of only $3.9 \pm 2.6$ months (19 intervals, median $=3.5$, range $=1-10)$ in which to transfer before conceiving again (Harcourt et al. 1980; Watts 1990b; Robbins et al. 2008). Intergroup encounters occur only about once a month in this population, and those tallies include mere auditory interactions at distances up to $500 \mathrm{~m}$, which reduces the chances of female transfer (Watts 1989; Sicotte 1993, 2001). Resident silverbacks may further reduce female transfer opportunities by herding them during encounters, particularly in multimale groups (Sicotte 1993).

Thirdly, a female preference for multimale groups may not have evolved in this population. Multimale groups are rare among western lowland gorillas (Parnell 2002; Magliocca et al. 1999), and they may be a relatively recent 
development in the evolutionary history of mountain gorillas (Harcourt 1995; Nunn et al. 2001; Robbins and Robbins 2005). Watts (2000) found that the destinations of female transfers are biased toward multimale groups versus one-male groups and lone silverbacks, but that conclusion may be sensitive to assumptions about the availability of potential transfer destinations. Whereas Watts (2000) showed whether the transfers differed from the proportions of potential destinations, we also test whether they differed from the relative probability of encountering those potential destinations. Because encounters are so rare for mountain gorillas, a female may have a greater chance of joining a group that she sees more often. We also present analyses of female immigration and emigration rates, which may be less sensitive to assumptions about potential destinations. We discuss the results within the context of the socioecological models, and the folivore paradox(es), and in comparison with other folivorous primates.

\section{Materials and methods}

\section{Dataset}

Data were evaluated for the mountain gorilla population of the Virunga Volcano region of Rwanda, Uganda, and Democratic Republic of Congo from 15 September 1967 until 31 December 2005. The data come from 11 groups that have been habituated by the Dian Fossey Gorilla Fund International for long-term research and from one group that has been habituated for tourism (Table 1). Each of the current study groups is generally observed on a daily basis, but before 1980 it was more typical to monitor only one group per day, and all observations have been interrupted at times (e.g., during the civil unrest in 1997-1998). The longterm records may miss infants who died shortly after birth, as well as females who left a group shortly after arriving, especially when groups were monitored less often.

Unless otherwise stated, all analyses are limited to voluntary transfers, so we excluded three group fissions that involved 20 involuntary moves by 20 different females and four group disintegrations that involved 14 involuntary moves by 12 different females. There have been 46 events when a female transferred by herself, five events when two females transferred simultaneously (ten emigrations), and one event when five females transferred together. Relationships among female mountain gorillas are weak, so simultaneous transfers by multiple females are treated as separate data points. Of the 61 cases of assumed voluntary emigration, 47 (77\%) were confirmed by locating the female in another group. In another eight cases (13\%), the records refer to a likely destination, but they do not explicitly state whether the female was seen there. No health problems were reported for the remaining six females $(10 \%)$, and dispersal is more common than death in this population, so it is the more likely explanation for the unexplained disappearances.

\section{Calculations}

Because female transfers occur only during encounters with other social units, we first examined temporal variations in the type of units encountered. For each study group with at

Table 1 Summary of the study groups

\begin{tabular}{|c|c|c|c|c|c|c|c|c|c|c|c|}
\hline \multirow[b]{2}{*}{ Group } & \multicolumn{2}{|c|}{ Years observed } & \multicolumn{4}{|l|}{ Total } & \multirow[b]{2}{*}{ Group-years } & \multirow[b]{2}{*}{ Female-years } & \multirow[b]{2}{*}{ Births } & \multirow[b]{2}{*}{ Imm } & \multirow[b]{2}{*}{ Em } \\
\hline & First & Last & Size & $\mathrm{AF}$ & SB & $\mathrm{mmg} \%$ & & & & & \\
\hline am & 1971 & 1971 & 2.0 & 1.0 & 1.0 & $0 \%$ & 0.2 & 0.2 & & & 1 \\
\hline $\mathrm{bm}$ & 1985 & 2005 & 19.6 & 6.2 & 2.9 & $95 \%$ & 20.4 & 126.9 & 29 & 3 & 4 \\
\hline $\mathrm{g} 4$ & 1967 & 1979 & 11.0 & 4.0 & 1.3 & $21 \%$ & 11.3 & 45.8 & 9 & 2 & 7 \\
\hline g5 & 1967 & 1993 & 17.6 & 6.6 & 2.2 & $83 \%$ & 25.7 & 168.8 & 43 & 14 & 11 \\
\hline g8 & 1967 & 1974 & 4.1 & 0.7 & 1.7 & $60 \%$ & 6.7 & 4.6 & 1 & 3 & 2 \\
\hline nk & 1972 & 1985 & 10.6 & 4.9 & 1.0 & $0 \%$ & 11.2 & 54.2 & 15 & 5 & 9 \\
\hline $\mathrm{pb}$ & 1993 & 2005 & 40.5 & 15.6 & 3.1 & $100 \%$ & 12.6 & 196.4 & 53 & 11 & 5 \\
\hline pn & 1975 & 1992 & 6.0 & 0.0 & 2.2 & $74 \%$ & 14.0 & 0.6 & & & 1 \\
\hline sh & 1993 & 2005 & 21.3 & 6.2 & 3.8 & $62 \%$ & 12.6 & 78.2 & 19 & 3 & 2 \\
\hline $\mathrm{sm}$ & 1971 & 1976 & 2.0 & 1.0 & 1.0 & $0 \%$ & 2.8 & 2.8 & 1 & 1 & 3 \\
\hline su & 1978 & 2005 & 26.5 & 9.1 & 2.6 & $95 \%$ & 27.3 & 248.0 & 64 & 10 & 15 \\
\hline $\operatorname{tg}$ & 1984 & 1987 & 2.5 & 1.0 & 1.0 & $0 \%$ & 2.1 & 2.1 & 1 & & 1 \\
\hline
\end{tabular}

First and last year of observation for this study. Average composition of each group includes the number of adult females (AF) and silverbacks (SB); as well as the proportion of months that it was multimale versus one male (mmg\%). Number of group-years (excluding time as a solitary male) and female-years for each group. Number of observed births, immigrations (imm), and emigrations (emg) 
least 50 reported encounters (and for the overall dataset), we calculated parameters for the following logistic regression equations:

$\operatorname{Logit}\left(P_{\mathrm{LG}}\right)=\mathrm{LG}_{0}+\mathrm{LG}_{1} \times$ date $+\mathrm{LG}_{2} \times\left(\right.$ date $\left.^{2}\right)$

$$
\operatorname{Logit}\left(P_{\mathrm{OM}}\right)=\mathrm{OM}_{0}+\mathrm{OM}_{1} \times \text { date }+\mathrm{OM}_{2} \times\left(\text { date }^{2}\right)
$$

in which $P_{\mathrm{LG}}$ is the relative probability of encountering a lone silverback versus a group; $P_{\mathrm{OM}}$ is the relative probability of encountering a one-male group versus a multimale group (excluding encounters with lone silverbacks); "date" is the date of the encounter, and $\mathrm{LG}_{0}, \mathrm{LG}_{1}$, $\mathrm{LG}_{2}, \mathrm{OM}_{0}, \mathrm{OM}_{1}$, and $\mathrm{OM}_{2}$ are the parameters that were calculated by the logistic regressions (Table 2). For logistic regressions using Eq. 1, we assigned a value of " 0 " for each encounter with a group and " 1 " for each encounter with a lone silverback. Similarly, for Eq. 2, we assigned a value of " 0 " for each encounter with a multimale group and " 1 " for each encounter with a one-male group. The probabilities calculated from these logistic regression equations $\left(P_{\mathrm{LG}}\right.$ and $\left.P_{\mathrm{OM}}\right)$ were then used in the analyses of immigration rates, emigration rates, and transfer destinations (along with the "date" variable to directly examine temporal variations). For research groups with less than 50 reported encounters, we used the parameters for the overall dataset, but the tourist group is excluded because its encounters are not reported and its range has little overlap with the research groups.

The analysis of immigration rates involved pooling the data in a separate fashion for each independent variable. To evaluate the effects of group type on immigration rates, we tallied the number of immigrations into one-male versus multimale groups and the number of group-months that each group type was observed. We calculated the expected number of immigrations into each group type, based on the null hypothesis that the observed immigrations would be distributed between the two group types in proportion to the number of group-months that each group type was observed. We then used rate-based $\chi^{2}$ calculations to compare the expected versus actual number of immigrations (Altmann and Altmann 1977).

To evaluate the effects of group size on immigration rates, we lumped the data into intervals of six (e.g., groups with one to six gorillas, seven to $12,13-18$, etc). We then tallied the number of immigrations at each size interval and divided by the number of group-months observed at those sizes. We then performed a linear regression of those immigration rates versus size. In those linear regressions, each data point was weighted according to the number of group-months that it represents because rates are less prone to demographic stochasticity when they are based on longer observations (Chatterjee and Price 1991).

In the analyses of emigration versus group type, we ran $\chi^{2}$ tests to compare the number of transfers versus births by females in each category. Each voluntary transfer can be considered a "decision" not to reproduce in the current group, so conversely each birth can be considered a decision not to transfer. We define the "emigration frequency" as the number of transfers divided by the number of decisions (transfers plus births). For each of the continuous independent variables, we performed logistic regressions in which the dependent variable equaled 1 when the female transferred and 0 when she stayed and conceived.

To look for biases in the destinations of female dispersal, Watts (2000) compared transfers to multimale groups versus one-male "units," which included both one-male groups and lone silverbacks. In addition to retaining those categories, we also examined lone silverbacks separately from groups. Watts (2000) tested whether the proportion of transfers to each type of destination differed from the proportions of those potential destinations in the study area

Table 2 Logistic regression parameters for temporal variations of encounters between the research groups and another social unit

\begin{tabular}{|c|c|c|c|c|c|c|}
\hline \multirow[b]{2}{*}{ Group } & \multicolumn{3}{|c|}{ Lone silverbacks versus groups } & \multicolumn{3}{|c|}{ One-male groups versus multimale groups } \\
\hline & $\mathrm{LG}_{0}$ & $\mathrm{LG}_{1}$ & $\mathrm{LG}_{2}$ & $\mathrm{OM}_{0}$ & $\mathrm{OM}_{1}$ & $\mathrm{OM}_{2}$ \\
\hline All & $2.4 \times 10^{4}$ & -23.9 & $6.0 \times 10^{-3}$ & $2.0 \times 10^{2}$ & $-1.0 \times 10^{-1}$ & \\
\hline g4 & $-8.5 \times 10^{-1}$ & & & $-1.6 \times 10^{3}$ & $8.3 \times 10^{-1}$ & \\
\hline g5 & -1.3 & & & $5.4 \times 10^{2}$ & $-2.7 \times 10^{-1}$ & \\
\hline $\mathrm{Nk}$ & $-1.8 \times 10^{5}$ & $1.8 \times 10^{2}$ & $-4.6 \times 10^{-2}$ & $-6.9 \times 10^{-1}$ & & \\
\hline $\mathrm{Bm}$ & $-1.6 \times 10^{2}$ & $7.8 \times 10^{-2}$ & & $4.8 \times 10^{2}$ & $-2.4 \times 10^{-1}$ & \\
\hline Sh & $2.2 \times 10^{5}$ & $-2.2 \times 10^{2}$ & $5.5 \times 10^{-2}$ & -1.8 & & \\
\hline $\mathrm{Pb}$ & $-7.9 \times 10^{2}$ & $4.0 \times 10^{-1}$ & & $4.8 \times 10^{5}$ & $-4.8 \times 10^{2}$ & $1.2 \times 10^{-1}$ \\
\hline
\end{tabular}

The parameters shown are from Eqs. 1 and 2 of the "Materials and methods." Values for regression coefficients (e.g., LG $\left.\mathrm{LG}_{1}, \mathrm{LG}_{2}\right)$ are presented and used only when the term is statistically significant $(p<0.05)$; otherwise, only the constant is shown (e.g., $\left.\mathrm{LG}_{0}\right)$. For example, group "g4" had no significant temporal variations in its probability of encountering a lone silverback versus a group, but a linear term was significant in the logistic regression for its probability of encountering a one-male versus multimale group 
and throughout the Virungas. In addition to using his expected values, we also tested whether the proportion of transfers differed from the relative probability of encountering each type of destination. Thus, we placed more emphasis on potential destinations that a female was more likely to encounter.

Unless otherwise indicated, we used $t$ tests for univariate analyses when the dependent variable was continuous and $\chi^{2}$ tests when it was dichotomous. We used general linear models for multivariate analyses when the dependent variable was continuous and logistic regressions when it was dichotomous. Data were not always available for each value of each variable, as reflected in the different sample sizes reported for various analyses. The rate-based $\chi^{2}$ tests and $G$ tests were performed with an Excel spreadsheet, and all other statistical analyses were performed using Systat 11 (2004, SYSTAT Software Inc., Richmond, CA, USA).

\section{Sample sizes}

The emigration frequency has been higher for nulliparous females than for parous females, which may reflect the additional time that they have to encounter potential destinations (unpublished data). Nulliparous females often transfer more than a year before their first conception, whereas parous females typically have only a few months after the death or weaning of their previous offspring (Harcourt 1978; Robbins et al. 2008). To avoid any bias from this possible influence, analyses of emigration frequencies in this paper were limited to all parous females (Table 3). Hypothetically, those remaining results could also be influenced by inbreeding avoidance, but the emigration frequency of natal parous females was not significantly different from nonnatal parous females (unpublished data). By retaining both categories of parous females in the analyses, we were also able to include parous females whose

Table 3 Sample sizes for births, immigrations, emigrations, and transfer destinations in the long-term records

\begin{tabular}{lrccc}
\hline $\begin{array}{l}\text { Female } \\
\text { category }\end{array}$ & Births & Immigrations & Emigrations & $\begin{array}{l}\text { Transfer } \\
\text { destinations }\end{array}$ \\
\hline Nulliparous & & & & \\
$\quad$ Natal & 21 & 19 & 25 & 13 \\
Nonnatal & 29 & 8 & 7 & 5 \\
Unknown & 4 & 2 & 2 & 1 \\
Subtotal & 54 & 29 & 34 & 19 \\
Parous & & & & \\
Natal & 25 & 2 & 17 & 2 \\
Nonnatal & 133 & 11 & 8 & 9 \\
Unknown & 22 & 10 & 27 & 7 \\
Subtotal & 180 & 23 & 61 & 37 \\
Total & 234 & 52 & & \\
\hline
\end{tabular}

natal group was unknown, which were especially common during the early years of the study.

Natal females reportedly mate with relatives other than their putative father (Watts 1990b, unpublished data), so inbreeding is generally not expected to influence their choice of transfer destinations. Similarly, the socioecological models do not predict different transfer preferences for nulliparous versus parous females (Wrangham 1980; van Schaik 1989; Sterck et al. 1997; Steenbeek and van Schaik 2001). Therefore, to maximize sample sizes for analyses of immigration rates and transfer destinations, we included all categories of transferring females, regardless of whether they were nulliparous or parous and natal or nonnatal (e.g., as in Watts 2000; Stokes et al. 2003).

Four of the study groups (Am, Nk, Sm, and Ti) were formed when a female transferred to a lone silverback. Lone silverbacks have not been monitored consistently, so the analyses of immigration rates would be biased if we selectively included the successful ones. To reduce this bias, we counted observation-months and immigrations only for groups, and we did not count the nine immigrations that formed groups from lone silverbacks. Even with this adjustment, the immigration rates may still be biased if immigrations and growth increased the likelihood that two groups ( $\mathrm{Nk}$ and $\mathrm{Su}$ ) became part of the dataset. The analyses of transfer destinations exclude nine emigrations in which the destination was unknown, so those results could be biased if unknown destinations are more likely to be lone silverbacks or small one-male groups. However, encounters with those destinations could also be missed, so the net bias may be minimized.

\section{Results}

Female transfers occur only during encounters with other social units, so we first examined temporal variations in the type of units encountered by each of the study groups. We then incorporated those results into analyses of how female dispersal may be influenced by group size and group type, the two main variables in the second folivore paradox. We examined female dispersal from three perspectives: emigration frequencies, immigration rates, and transfer destinations.

Encounters with another unit

From 1973 to 2005, the long-term records show 350 encounters (48\%) between a study group and a multimale group, 213 encounters (28\%) with a one-male group, 27 encounters (4\%) with a group of unknown type, and 143 encounters $(20 \%)$ with a lone silverback. The probability of encountering a one-male group (versus a multimale group) 
declined significantly during the study period, from $80 \%$ in the mid-1970s to $5 \%$ in 2005 (Fig. 2). The largest fluctuations occurred around in 1993, when a multimale group (g5) split into another multimale group ( $\mathrm{Pb}$ ) plus a one-male group (Sh), so the moving averages in Fig. 2 do not fully illustrate how abruptly the proportions can change. The proportion of encounters with lone silverbacks (versus groups) has fluctuated over a narrower range, but the temporal pattern can still be fit with a logistic equation using a linear and quadratic term (Table 4).

In addition to those temporal variations in encounters by the study groups, there were significant differences among groups at the same time. For example, since the fission of g5 in 1993, the three major research groups have had significant differences in their proportions of encounters with multimale groups, one-male groups, and lone silverbacks (Table 5). Intergroup differences may reflect the way their home ranges overlap with other groups and lone silverbacks. The differences also reflect the fact that a group does not encounter itself. For example, $\mathrm{Pb}$ had more encounters with one-male groups than Sh because Sh was the one-male group for many of those encounters. Finally, the temporal and spatial variations may reflect fluctuations in the degree of human disturbances as well as demographic stochasticity (e.g., Plumtpre and Williamson 2001; Robbins and Robbins 2004).

\section{Emigration frequencies of parous females}

The second folivore paradox asks why females would accept a greater risk of infanticide by staying in (smaller) one-male groups if the costs of within-group scramble competition are minimal in larger (multimale) groups. The first potential explanation was that previous studies of

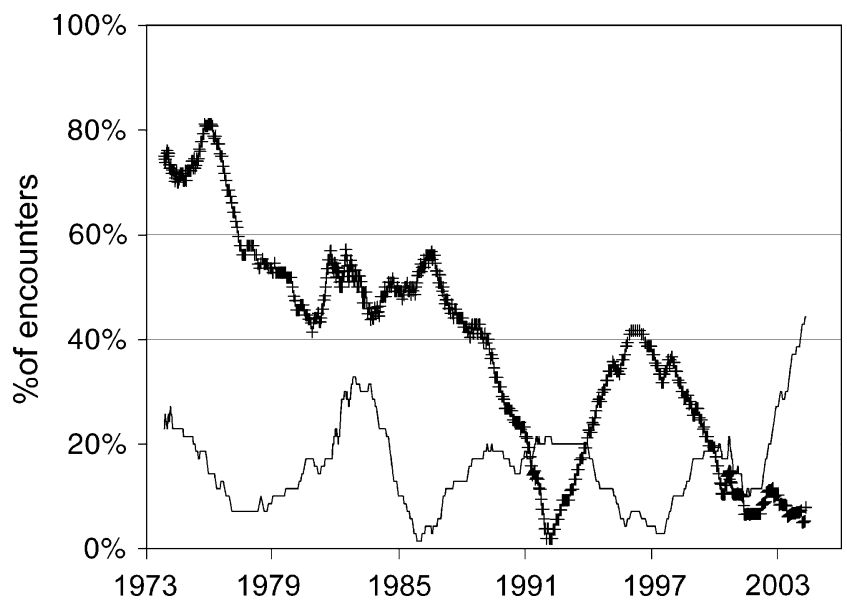

Fig. 2 Temporal variations in encounters by the study groups. For each data point, the value of the date is the moving average of 70 encounters. The $y$-axis shows the proportion of those encounters that were with one-male groups versus multimale groups (plus signs) and with lone silverbacks versus groups (line) female reproductive success may not fully reflect the influence of within-group scramble competition because such competition has more influence upon dispersal. If dispersal was influenced by scramble competition within groups, then we would expect the emigration frequency to increase with group size. Instead, the emigration frequency was significantly lower in larger groups, thus providing no evidence of within-group scramble competition (Table 4). Parous females transferred during 17 of 53 "decisions" in one-male groups $(32 \%)$, and they stayed and conceived in the other $68 \%$ of those decisions. Those results illustrate that females are staying and conceiving in one-male groups, despite the apparent lack of scramble competition within larger (multimale) groups.

The second possible explanation for those results was that females lack opportunities to transfer to multimale groups. For example, if a group became one male while a female was lactating or pregnant, she might not transfer immediately due to the risk of infanticide to her offspring. After a female conceived in a multimale group, the group became one male for only 40 of the 660 female-years $(6 \%)$ until her next conception or transfer. After a female conceived in a one-male group, the group remained one male during 97 of 142 female-years (69\%) until her next conception or transfer. Therefore, of the 137 female-years that were observed in one-male groups, 40 female-years (29\%) occurred before the female had an opportunity to transfer in response to a change in group structure. Thus, less than half the time that females spent in one-male groups could be explained by their inability to transfer while lactating or pregnant. Even that proportion is probably an overestimate in comparison with the broader population because the study groups have been multimale more often.

After the death or weaning of an offspring, a female might still lack opportunities to join a multimale group, if encounters with those groups are lacking. Yet when parous females stayed in a one-male group, their probability of encountering a multimale group was $55 \% \pm 21 \%$, which is significantly higher than the $39 \% \pm 20 \%$ probability when they left a one-male group (Table 4). These results are counter to any expectations that females stay in one-male groups because they lack encounters with multimale groups.

The third potential explanation to the second folivore paradox is that a female preference for multimale groups may not have evolved in this population. Yet parous females transferred during only ten of $154(6 \%)$ decisions in multimale groups, which is significantly less than the 17 of 53 decisions $(32 \%)$ in which they left one-male groups (Table 4). This fivefold difference is consistent with a female preference for multimale groups. However, parous females were significantly less likely to emigrate when they 
Table 4 Details from statistical analyses of encounters with another type of social unit, immigration rates by all females ( $\left.I_{\mathrm{RATE}}\right)$, emigration frequencies by parous females $\left(E_{\mathrm{FREQ}}\right)$, and transfer destinations

\begin{tabular}{lll}
\hline Dependent variable & Independent variable & Statistics details \\
\hline$P_{\mathrm{OM}}$ & Date & Logistic $\chi^{2}=89.7, d f=1, N=563, p<0.001$ \\
$P_{\mathrm{LG}}$ & Date & Logistic $\chi^{2}=31.2, d f=2, N=733, p<0.001$ \\
$E_{\mathrm{FREQ}}$ & Group size & Logistic $\chi^{2}=20.3, d f=1, N=207, p<0.001$ \\
$P_{\mathrm{MX}}$ & $E_{\mathrm{FREQ}}$ & $t$ test: $t=2.4, d f=37, p=0.024$ \\
$E_{\mathrm{FREQ}}$ & Group type & $\chi^{2}=22.8, N=207, d f=1, p<0.001$ \\
$E_{\mathrm{FREQ}}$ & $P_{\mathrm{MX}}$ & Logistic $\chi^{2}=5.1, d f=1, N=139, p=0.023$ \\
$E_{\mathrm{FREQ}}$ & $P_{\mathrm{LG}}$ & Logistic $\chi^{2}=2.8, d f=1, N=139, p=0.091$ \\
Group size & Group type & $t$ test: $t=8.6, d f=205, p<0.001$ \\
$I_{\mathrm{RATE}}$ & Group size & $R^{2}=0.062, F_{8}, 1=0.53, p=0.49$ \\
$I_{\mathrm{RATE}}$ & $P_{\mathrm{OX}}$ & $R^{2}=0.068, F_{6}, 1=0.44, p=0.53$ \\
$I_{\mathrm{RATE}}$ & $P_{\mathrm{LG}}$ & $R^{2}=0.031, F_{8}, 1=0.26, p=0.63$ \\
$I_{\mathrm{RATE}}$ & Group type & Rate-based $\chi^{2}=1.1, d f=1, p=0.29$ \\
$T_{\mathrm{OM}}$ & Date & Logistic $\chi^{2}=6.6, d f=1, N=37, p=0.010$ \\
$T_{\mathrm{OM}}$ & $P_{\mathrm{OM}}$ & Logistic $\chi^{2}=14.5, d f=1, N=37, p<0.001$ \\
$T_{\mathrm{LG}}$ & Date & Logistic $\chi^{2}=2.1, d f=1, N=37, p=0.14$ \\
$T_{\mathrm{LG}}$ & $P_{\mathrm{LG}}$ & Logistic $\chi^{2}=3.1, d f=1, N=37, p=0.08$ \\
\hline
\end{tabular}

$P_{\mathrm{LG}}$ is the relative probability of encountering a lone silverback versus a group, and $P_{\mathrm{OM}}$ is the relative probability of encountering a one-male group versus a multimale group (excluding encounters with lone silverbacks). $T_{\mathrm{LG}}$ and $T_{\mathrm{OM}}$ are the corresponding probabilities that a transfer went to those types of destinations. $P_{\mathrm{OX}}$ and $P_{\mathrm{MX}}$ are the relative probabilities of encountering a one-male group or a multimale group (respectively) versus all other social units

had a higher relative probability of encountering a multimale group versus other units (Table 4). Those disparate results might suggest that females stayed in multimale groups because most of their encounters were with other multimale groups. Yet in a multivariate analysis, emigration rates remained significantly lower in multimale groups, even after accounting for the types of social units encountered (Table 6). One reason for those results is that even when intergroup encounters were mostly with multimale groups, the study groups continued to encounter lone silverbacks too. The emigration frequency was not significantly correlated with the relative probability of encountering a lone silverback versus a group (Table 4), so we found no reason to disregard those potential destinations.

An underlying assumption in the second folivore paradox is that multimale groups will generally be larger than one-

Table 5 Number of encounters by each research group with each type of social unit since May 1993, when two of those groups were formed

\begin{tabular}{lrrrr}
\hline & $\mathrm{Bm}$ & $\mathrm{Pb}$ & $\mathrm{Sh}$ & Total \\
\hline Lone silverbacks & 13 & 25 & 13 & 51 \\
Multimale groups & 35 & 39 & 69 & 143 \\
One-male groups & 6 & 21 & 11 & 38 \\
Total & 54 & 85 & 93 & 232 \\
\hline
\end{tabular}

The differences among groups are significantly different from the null hypothesis, which is that the relative proportions for each research group will not differ from the total proportions for all three groups together $\left(\chi^{2}=16.5, d f=4, p=0.0024\right)$ male groups because additional females make it more difficult for one male to monopolize reproduction. Our study supports that assumption because the group size averaged $28.3 \pm 11.1$ gorillas during decisions in multimale groups, which is significantly higher than the $13.9 \pm 8.4$ gorillas during decisions in one-male groups (Table 4). Because group size and group type were covariant, the unexpected decline in emigration from larger groups might hypothetically arise because those groups are primarily multimale. Yet in a multivariate analysis, emigration rates remained significantly lower in larger groups, even after accounting for the fact that those groups are multimale (Table 6). So

Table 6 Statistical details for two multivariate logistic regressions of emigration frequencies, which was assigned a value of 1 when the female transferred and 0 when she stayed and conceived

\begin{tabular}{lccrc}
\hline Parameter & Estimate & Standard error & $t$ ratio & $p$ value \\
\hline Logistic $\chi^{2}=19.1, d f=2, p<0.001$ & & & \\
Constant & 2.33 & 0.99 & 2.36 & 0.018 \\
Group type & -1.97 & 0.55 & -3.59 & 0.000 \\
$P_{\mathrm{MX}}$ & -2.20 & 1.22 & -1.80 & 0.072 \\
Logistic $\chi^{2}=25.7, d f=2, p<0.001$ & & & \\
Constant & 1.23 & 0.69 & 1.78 & 0.075 \\
Group type & -1.19 & 0.52 & -2.29 & 0.022 \\
Group size & -0.06 & 0.03 & -2.31 & 0.021 \\
\hline
\end{tabular}

The parameter for group type was assigned a value of one for onemale groups and two for multimale groups. $P_{\mathrm{MX}}$ is the relative probability of encountering a multimale group versus all other social units 
again these emigration results provide no evidence of scramble competition within larger groups.

Rates of immigration by all females

Although emigration frequencies are expected to reflect female transfer preferences, they may also reflect other influences upon dispersal, such as herding by resident males. For a second perspective on female transfer preferences, we examined immigration rates into the study groups. A total of 52 immigrations by all females occurred during the 147 group-years observed, for an average rate of 0.353 immigrations per group-year. If dispersal was influenced by scramble competition within groups, we would expect larger groups to have lower immigration rates. Yet the immigration rate was not significantly correlated with group size, thus indicating no evidence of such competition (Table 4).

If females preferred to stay in multimale groups to reduce the risk of infanticide, we might expect low immigration into the study groups when they were encountering mostly multimale groups. We would also expect lower immigration rates when more encounters were with lone silverbacks (who have no females for transfer). If immigration rates are relatively low from encounters with multimale groups and lone silverbacks, then they should seem relatively high from encounters with one-male groups, which is the only other type of social unit for comparison. Nonetheless, the immigration rate was not significantly correlated with the probability of encountering one-male groups versus multimale groups and lone silverbacks (Table 4).

If females preferred to join multimale groups, we would expect those groups to have higher immigration rates. The immigration rate was 0.389 immigrations per group-year during 103 group-years of multimale groups, which is $42 \%$ higher than the rate of 0.274 during 44 group-years of onemale groups, but the difference is not significant (Table 4). No combination of variables was significant in multivariate analyses. Thus, the immigration rates provided no significant evidence that dispersal is influenced by group type. Any influences on immigration rates may be obscured by variations in the number of potential immigrants, which was not tested because such information was generally unknown for the neighboring nonstudy groups.

\section{Destinations of transfers by all females}

As a third perspective on female transfer preferences, we examined the destinations of those transfers. Of the 61 female transfers from a study group, 30 went to a multimale group, six to a one-male group, 12 to a lone silverback, and 13 to an unknown type of destination. Transferring females were significantly more likely to join a one-male (versus multimale) unit during the early years of the study and when they were more likely to encounter such units at the time of their transfer (Table 4). Thus, the temporal variations in transfers to one-male versus multimale units could be explained by variations in the relative probability of encountering those units. Overall, the number of transfers to one-male units was not significantly different from expected values based on the relative probability of encountering such units $\left(G_{\text {adj }}=0.50, p=0.48\right.$, Table 7), even after considering the type of group that the female was leaving $\left(G_{\text {adj }}=1.7, p=0.63\right)$.

In contrast, when expected values were based on the proportions of each type of unit (Watts 2000), the transfer destinations were significantly biased toward multimale units $\left(G_{\text {adj }}=21.2-23.0, p<0.001\right)$. Multimale units were expected to receive $21-25 \%$ of transfers when based on the proportion of those units, versus an expected value of $45 \%$ based on the proportion of encounters with those units. Thus, encounters with multimale units were more frequent than expected from their proportions, which occurred because the study groups were disproportionately multimale and because they encountered each other more often than the nonstudy units. From this perspective, the apparent bias toward multimale units may have arisen merely because the females have encountered those units more frequently.

Transfers to lone silverbacks (versus a group) were not significantly correlated with the date of transfer nor with the relative probability of encountering each type of destination (Table 4). In addition, the overall number of transfers to lone silverbacks was not significantly different from the values expected from the proportion of encounters with such males $\left(G_{\text {adj }}=0.89, p=0.35\right)$. Thus, there is no apparent preference or aversion for transferring females to join lone silverbacks.

\section{Discussion}

The second folivore paradox is characterized by a population in which the costs of scramble competition are minimal

Table 7 Dispersal destinations and expected values (in parentheses) versus the group type for the source of each transfer

\begin{tabular}{lrr}
\hline Destination & \multicolumn{2}{c}{ Group type for source of transfer } \\
\cline { 2 - 3 } & One male & Multimale \\
\hline Lone silverbacks & $10(6.1)$ & $2(3.4)$ \\
One-male groups & $5(8.9)$ & $1(1.9)$ \\
Multimale groups & $9(9.1)$ & $10(7.7)$ \\
\hline
\end{tabular}

For the analyses in the text, transfers to one-male groups were lumped with either lone silverbacks (for the comparison of one-male versus multimale units) or with established groups (for the comparison of lone silverbacks versus groups) 
within large multimale groups, yet females stay in smaller one-male groups that pose a greater risk of infanticide. In combination with previous census data and analyses of female reproductive success (Kalpers et al. 2003; Robbins et al. 2007), this study has provided additional evidence that the second folivore paradox applies to mountain gorillas in the Virunga Volcano Region. Females were not more significantly likely to emigrate from larger groups, and the immigration rate was not significantly greater into smaller groups. Those results suggest that scramble competition within groups has no significant influence on female dispersal, just as it showed no significant influence on female reproductive success (Robbins et al. 2007). Despite this apparent lack of scramble competition within large multimale groups, females in smaller one-male groups emigrated in only $32 \%$ of their "decisions" and in the other $68 \%$ they stayed and conceived again. Those results are qualitatively consistent with census data showing that most adult females are found in one-male groups (e.g., Weber and Vedder 1983; Sholley 1989). Previous studies have also shown that the risk of infanticide is significantly higher in one-male groups than multimale groups (Fossey 1984; Watts 1989; Robbins et al. 2007), so collectively this evidence supports all of the components of the second folivore paradox. Below, we examine the evidence in greater detail and we explore the potential explanations for resolving of the second folivore paradox.

\section{Within-group scramble competition}

The first potential explanation for the apparent folivore paradox was that previous studies of female reproductive success did not fully reflect the influences of within-group scramble competition for this population. We suggested that female dispersal might be more sensitive to within-group scramble competition, yet we still found no such evidence, even as the study groups have become three to five times larger than the population average. These results should further diminish any consideration of within-group scramble competition for this population. In contrast with our results, feeding competition may explain why female olive colobus monkeys were more likely to join smaller one-male groups (Korstjens and Schippers 2003). Juvenile red howler monkeys were more likely to leave larger groups, but those results may reflect infanticide risks more than within-group scramble competition (Crockett and Pope 1993; Crockett and Janson 2000).

One potential caveat for this study is that it focused on groups that have better habitat than the rest of the Virungas (McNeilage 1995) and have less reliance on contestable resources than other gorillas (Doran et al. 2002; Robbins and McNeilage 2003; Robbins 2008a). Thus, our results may not be representative of other populations of mountain gorillas or of western lowland gorillas. For example, western lowland gorillas might be a better example of the original folivore paradox, even though they are more frugivorous than the Virunga mountain gorillas. Western gorillas still have natural predators; they have essentially no multimale groups, and their maximum group size seems to be more limited (Parnell 2002; Magliocca et al. 1999; Fay et al. 1995). Yet the cause of such limitations is unknown because birth rates did not decline significantly in larger groups (Stokes et al. 2003). Initial data have shown mixed results for the effect of group size on their female dispersal (ibid).

\section{Transfer opportunities}

The second potential explanation for the second folivore paradox was that female mountain gorillas may have limited opportunities to join multimale groups, especially because they do not transfer while lactating or pregnant due to the risk of infanticide (Robbins et al. 2008; see also Sterck 1997; Sterck et al. 2005). Yet less than half of the time that females spent in one-male groups could be attributed to their inability to transfer while lactating or pregnant. Furthermore, even after they were no longer constrained by dependent offspring, females in one-male groups transferred in only $32 \%$ of their decisions, so it is questionable whether the dependent offspring had been the only reason why the female had not left earlier. The probabilities of encountering multimale groups were higher for females who stayed in one-male groups than for those who left, so those females generally did not seem limited by a lack of encounters.

Even if limited transfer opportunities account for some proportion of the time that females currently spend in onemale groups, such an explanation can become circular when applied to an evolutionary timescale. Social structure is expected to be determined first by the distribution of females, which in turn determines the distribution of males (Emlen and Oring 1977; Altmann 1990; Lindenfors et al. 2004). If females avoided one-male groups more consistently, then it would become less rewarding for multimale groups to fission and for subordinate males to emigrate and become solitary. Multimale groups would become more common, and females would not lack opportunities to join them.

Female preference for multimale groups

The third potential explanation to the second folivore paradox is that a female preference for multimale groups may not have evolved in this population. Parous females left one-male groups five times more frequently than multimale groups, but immigration into multimale groups 
was not significantly higher, and analyses of transfer destinations yielded mixed results. The latter two tests are less conclusive due to incomplete information about the number of potential immigrants and potential transfer destinations. Conversely, the frequency of herding has been more than five times higher in multimale groups than onemale groups $(18 \%$ versus $2 \%)$, which could explain the fivefold difference in emigration frequencies (Sicotte 1993, 2001). If the risk of injury from herding and male coercion can represent a substantial cost of dispersal for female mountain gorillas, then they may not be able to transfer as freely as typically assumed for folivorous primates (Watts 1992; Sicotte 1994; Robbins 2008b). Thus, we cannot exclude the possibility that a female preference for multimale groups has not evolved in this population.

Phylogenetic inertia has received increasing attention in studies of primate socioecology (Thierry et al. 2000; Korstjens et al. 2002; Ossi and Kamilar 2006) and in studies of nonprimates such as cooperatively breeding birds (Edwards and Naeem 1993; Ekman and Ericson 2006), feral horses (Linklater 2000), and the yellow mongoose ( $\mathrm{Nel}$ and Kok 1999). Multimale groups are considered a relatively recent development in the evolutionary history of mountain gorillas because the species lacks characteristics of multimale species, such as large testes size, long estrous periods, and large female sexual swellings (Harcourt 1995; Nunn et al. 2001; Robbins and Robbins 2005). Multimale groups reportedly have less infanticide in many primate species (Janson and van Schaik 2000; but see Borries and Koenig 2000; Crockett and Janson 2000), yet we are unaware of other species where female transfers were biased toward such destinations.

\section{Other influences on female dispersal}

A fourth possible explanation for the second folivore paradox is that female dispersal is influenced by other factors. Established silverbacks with large multimale groups may retain their females by minimizing encounters with other groups, whereas younger males may seek mates more aggressively when they have few or none (Watts 1994b, 1998). Females might choose younger males as an alternative strategy to reduce infanticide (Sterck et al. 2005) or they may prefer males with particular morphological traits (Caillaud et al. 2008; Setchell 2005; Gontard-Danek and Moller 1999; Shackleton et al. 2005). Females may distribute their reproduction over a variety of settings as a bet-hedging strategy, especially if the advantage of any particular setting is hard to evaluate (Philippi and Seger 1989; Sicotte 2001). Females may disperse to escape habitat destruction or other human disturbances (Stewart and Harcourt 1987). Further study is needed to examine whether the dispersal of female mountain gorillas is influenced by these factors and whether such factors would reduce the prevalence of multimale groups in any species. Although this study has built on the prevailing socioecological theories for primates, mountain gorillas have also been compared with nonprimates such as gregarious equids, which can have female transfers, low feeding competition, and infanticide (Sterck et al. 1997; Watts 2000; Rubenstein and Hack 2004). The second folivore paradox could be considered for any species in which females stay in one-male groups despite the risk of infanticide.

Acknowledgements We appreciate the long-term commitment of the Rwanda Office of Tourism and National Parks for supporting the research activities at the Karisoke Research Center. We are greatly indebted to the many researchers and field assistants who during the past 40 years of research have contributed to the long-term demographic and behavioral databases of Karisoke. In particular, we highly commend the outstanding and tireless commitment of all Karisoke and ORTPN field staff to protect the mountain gorillas during the last four decades; without their efforts, this research would not be possible. We thank Maryke Gray, the International Gorilla Conservation Program, and the Ranger-Based Monitoring program for the use of the demographic data from the Susa Group. We thank Pascale Sicotte for providing compiled records of intergroup encounters. We thank David Watts and two anonymous reviewers for their helpful comments on an earlier version of this manuscript. We thank the various public and private agencies, foundations, and individuals that have provided support for the Karisoke Research Center since 1967. Max Planck Society provided support for data analysis and write up of the project.

Open Access This article is distributed under the terms of the Creative Commons Attribution Noncommercial License which permits any noncommercial use, distribution, and reproduction in any medium, provided the original author(s) and source are credited.

\section{References}

Alberts SC, Watts HE, Altmann J (2003) Queuing and queue-jumping: long-term patterns of reproductive skew in male savannah baboons, Papio cynocephalus. Anim Behav 65:821-840

Altmann SA (1962) A field study of the sociobiology of rhesus monkeys, Macaca mulatta. Ann Proc NY Acad Sci 102:338-435

Altmann J (1990) Primate males go where the females are. Anim Behav 39:193-195

Altmann SA, Altmann J (1977) Analysis of rates of behaviour. Anim Behav 25:364-372

Borries C, Koenig A (2000) Infanticide in hanuman langurs: social organization, male migration, and weaning age. In: van Schaik C, Janson C (eds) Infanticide by males and its implications. Cambridge University Press, Cambridge, pp 99-122

Caillaud D, Levrero F, Gatti S, Menard N, Raymond M (2008) Influence of male morphology on male mating status and behavior during interunit encounters in western lowland gorillas. Am J Phys Anthropol 135:379-388

Chapman CA, Pavelka MSM (2005) Group size in folivorous primates: ecological constraints and the possible influence of social factors. Primates 46:1-9

Chatterjee S, Price P (1991) Regression analysis by example, 2nd edn. Wiley-Interscience, New York 
Clutton-Brock TH (1989) Female transfer and inbreeding avoidance in social mammals. Nature 337:70-72

Crockett C, Janson C (2000) Infanticide in red howlers: female group size, male membership, and a possible link to folivory. In: van Schaik C, Janson C (eds) Infanticide by males and its implications. Cambridge University Press, Cambridge, pp 75-98

Crockett CM, Pope TR (1993) Consequences of sex differences in dispersal for juvenile red howler monkeys. In: Juvenile Primates: life history, development, and behavior. Oxford University Press, New York, pp 104-118

Dias LG, Strier KB (2003) Effects of group size on ranging patterns in Brachyteles arachnoides hypoxanthus. Int J Primatol 24:209-221

Doran DM, McNeilage A, Greer D, Bocian C, Mehlman P, Shah N (2002) Western lowland gorilla diet and resource availability: new evidence, cross-site comparisons, and reflections on indirect sampling methods. Am J Primatol 58:91-116

Edwards SV, Naeem S (1993) The phylogenetic component of cooperative breeding in perching birds. American Nat 141:754-789

Ekman J, Ericson PGP (2006) Out of Gondwanaland; the evolutionary history of cooperative breeding and social behaviour among crows, magpies, jays and allies. Proc Royal Soc B Biol Sci 273:1117-1125

Emlen ST, Oring LW (1977) Ecology, sexual selection, and evolution of mating systems. Science 197:215-223

Fay JM, Carroll R, Peterhans JCK, Harris D (1995) Leopard attack on and consumption of gorillas in the Central-African-Republic. J Hum Evol 29:93-99

Fossey D (1984) Infanticide in mountain gorillas (Gorilla gorilla beringei) with comparative notes on chimpanzees. In: Hausfater G, Hrdy S (eds) Infanticide: comparative and evolutionary perspectives. Aldine, Hawthorne, pp 217-236

Gillespie TR, Chapman CA (2001) Determinants of group size in the red colobus monkey (Procolobus badius): an evaluation of the generality of the ecological-constraints model. Behav Ecol Sociobiol 50:329-338

Gontard-Danek MC, Moller AP (1999) The strength of sexual selection: a meta-analysis of bird studies. Behav Ecol 10:476486

Harcourt AH (1978) Strategies of emigration and transfer by primates, with particular reference to gorillas. Z Tierpsychol 48:401-420

Harcourt AH (1995) Sexual selection and sperm competition in primates: what are male genitalia good for? Evol Anthropol 4:121-129

Harcourt AH, Greenberg J (2001) Do gorilla females join males to avoid infanticide? A quantitative model. Anim Behav 62:905-915

Harcourt AH, Stewart KJ (2007) Gorilla society: conflict, compromise, and cooperation between the sexes. University of Chicago Press, Chicago

Harcourt AH, Stewart KS, Fossey D (1976) Male emigration and female transfer in wild mountain gorilla. Nature 263:226-227

Harcourt AH, Fossey D, Stewart KG, Watts D (1980) Reproduction in wild gorillas and some comparisons with chimpanzees. J Reprod Fertil 28:59-70

Harcourt AH, Fossey D, Sabaterpi J (1981) Demography of Gorilla gorilla. J Zool 195:215-233

Hebblewhite M, Pletscher D (2002) Effects of elk group size on predation by wolves. Can J Zool 80:800-809

Hill RA, Lee PC (1998) Predation risk as an influence on group size in cercopithecoid primates: implications for social structure. J Zool 245:447-456

Isbell LA (1991) Contest and scramble competition: patterns of female aggression and ranging behavior in primates. Behav Ecol 2:143-155

Isbell LA, Young TP (2002) Ecological models of female social relationships in primates: similarities, disparities, and some directions for future clarity. Behaviour 139:177-202

Janson CH, Goldsmith ML (1995) Predicting group size in primatesforaging costs and predation risks. Behav Ecol 6:326-336
Janson CH, van Schaik CP (2000) The behavioral ecology of infanticide. In: Janson $\mathrm{CH}$, van Schaik CP (eds) Infanticide by males and its implications. Cambridge University Press, Cambridge, pp 469-494

Kalpers J, Williamson EA, Robbins MM, McNeilage A, Nzamurambaho A, Lola N, Mugiri G (2003) Gorillas in the crossfire: population dynamics of the Virunga mountain gorillas over the past three decades. Oryx 37:326-337

Koenig A (2002) Competition for resources and its behavioral consequences among female primates. Int J Primatol 23:759-783

Koenig A, Beise J, Chalise MK, Ganzhorn JU (1998) When females should contest for food - testing hypotheses about resource density, distribution, size, and quality with Hanuman langurs (Presbytis entellus). Behav Ecol Sociobiol 42:225-237

Korstjens AH, Schippers EP (2003) Dispersal patterns among olive colobus in Tai National Park. Int J Primatol 24:515-539

Korstjens AH, Sterck EHM, Noe R (2002) How adaptive or phylogenetically inert is primate social behaviour? A test with two sympatric colobines. Behaviour 139:203-225

Lindenfors P, Froberg L, Nunn CL (2004) Females drive primate social evolution. Proc Royal Soc London Series B Biol Sci 271: S101-S103

Linklater WL (2000) Adaptive explanation in socio-ecology: lessons from the Equidae. Biol Rev 75:1-20

Magliocca F, Querouil S, Gautier-Hion A (1999) Population structure and group composition of western lowland gorillas in northwestern Republic of Congo. Am J Primatol 48:1-14

McNeilage A (1995) Mountain gorillas in the Virunga volcanoes: ecology and carrying capacity. Ph.D. thesis. University of Bristol, Bristol

Nel JAJ, Kok OB (1999) Diet and foraging group size in the yellow mongoose: a comparison with the suricate and the bat-eared fox. Ethol Ecol Evol 11:25-34

Nunn CL, van Schaik CP, Zinner D (2001) Do exaggerated sexual swellings function in female mating competition in primates? A comparative test of the reliable indicator hypothesis. Behav Ecol 12:646-654

Ossi K, Kamilar JM (2006) Environmental and phylogenetic correlates of Eulemur behavior and ecology (Primates: Lemuridae). Behav Ecol Sociobiol 61:53-64

Parnell RJ (2002) Group size and structure in western lowland gorillas (Gorilla gorilla gorilla) at Mbeli Bai, Republic of Congo. Am J Primatol 56:193-206

Philippi T, Seger J (1989) Hedging ones evolutionary bets, revisited. Trends Ecol Evol 4:41-44

Plumtpre A, Williamson E (2001) Conservation-oriented research in the Virunga region. In: Robbins M, Sicotte P, Stewart K (eds) Mountain gorillas: three decades of research at Karisoke. Cambridge University Press, Cambridge, pp 361-390

Pusey A, Wolf M (1996) Inbreeding avoidance in animals. Trends Ecol Evol 11:201-206

Robbins MM (2008a) Feeding competition and agonistic relationships among Bwindi mountain gorillas. Int J Primatol 29:999-1018

Robbins MM (2008b) Male aggression toward females in mountain gorillas: courtship or coercion. In: Muller MN, Wrangham R (eds) Sexual coercion in primates. Harvard University Press, Cambridge

Robbins MM, McNeilage A (2003) Home range and frugivory patterns of mountain gorillas in Bwindi Impenetrable National Park, Uganda. Int J Primatol 24:467-491

Robbins MM, Robbins AM (2004) Simulation of the population dynamics and social structure of the Virunga mountain gorillas. Am J Primatol 63:201-223

Robbins AM, Robbins MM (2005) Fitness consequences of dispersal decisions for male mountain gorillas (Gorilla beringei beringei). Behav Ecol Sociobiol 58:295-309 
Robbins MM, Robbins AM, Gerald-Steklis N, Steklis HD (2007) Socioecological influences on the reproductive success of female mountain gorillas (Gorilla beringei beringei). Behav Ecol Sociobiol 61:919-931

Robbins AM, Stoinski TS, Fawcett KT, Robbins MM (2008) Does dispersal cause reproductive delays in female mountain gorillas? Behaviour (in press)

Rogovin K, Randall JA, Kolosova I, Moshkin M (2004) Predation on a social desert rodent, Rhombomys opimus: effect of group size, composition, and location. J Mammal 85:723-730

Rubenstein DI, Hack M (2004) Natural and sexual selection and the evolution of multi-level societies: insights from zebras with comparisons to primates. In: Kappeler PM, van Schaik C (eds) Sexual selection in primates: new and comparative perspectives. Cambridge University Press, New York, pp 288-303

Schaller GB (1963) The mountain gorilla: ecology and behavior. University of Chicago Press, Chicago

Setchell JM (2005) Do female mandrills prefer brightly colored males? Int J Prim 26:715-735

Shackleton MA, Jennions MD, Hunt J (2005) Fighting success and attractiveness as predictors of male mating success in the black field cricket, Teleogryllus commodus: the effectiveness of nochoice tests. Behav Ecol Sociobiol 58:1-8

Sholley C (1989) 1989 census of mountain gorillas in the Virungas of central Africa. In: Mountain gorilla project, Rwanda, p 7

Sicotte P (1993) Intergroup encounters and female transfer in mountain gorillas - influence of group composition on male behavior. Am J Primatol 30:21-36

Sicotte P (1994) Effect of male competition on male-female relationships in bi-male groups of mountain gorillas. Ethology 97:47-64

Sicotte P (2000) A case study of mother-son transfer in mountain gorillas. Primates 41:93-101

Sicotte P (2001) Female mate choice in mountain gorillas. In: Robbins M, Sicotte P, Stewart K (eds) Mountain gorillas: three decades of research at Karisoke. Cambridge University Press, Cambridge, pp 59-88

Snaith TV, Chapman CA (2007) Primate group size and interpreting socioecological models: do folivores really play by different rules? Evol Anthropol 16:94-106

Steenbeek R, van Schaik CP (2001) Competition and group size in Thomas's langurs (Presbytis thomasi): the folivore paradox revisited. Behav Ecol Sociobiol 49:100-110

Sterck EHM (1997) Determinants of female dispersal in Thomas langurs. Am J Primatol 42:179-198

Sterck EHM, Watts DP, van Schaik CP (1997) The evolution of female social relationships in nonhuman primates. Behav Ecol Sociobiol 41:291-309

Sterck EHM, Willems EP, van Hooff J, Wich SA (2005) Female dispersal, inbreeding avoidance and mate choice in Thomas langurs (Presbytis thomasi). Behaviour 142:845-868
Stewart K, Harcourt A (1987) Gorillas: variation in female relationships. In: Smuts B, Cheney D, Seyfarth R, Wrangham W, Struhsaker T (eds) Primate societies. University of Chicago Press, Chicago, pp $155-164$

Stokes EJ, Parnell RJ, Olejniczak C (2003) Female dispersal and reproductive success in wild western lowland gorillas (Gorilla gorilla gorilla). Behav Ecol Sociobiol 54:329-339

Struhsaker TT, Leland L (1988) Group fission in red tail monkeys (Cercopithecus ascanius) in the Kibale Forest, Uganda. In: Gautier-Hion A, Bourliere F, Gautier JP, Kingdon J (eds) A primate radiation: evolutionary history of the African guenons. Cambridge University Press, Cambridge, pp 364-388

Thierry B, Iwaniuk AN, Pellis SM (2000) The influence of phylogeny on the social behaviour of macaques (Primates: Cercopithecidae, genus Macaca). Ethology 106:713-728

van Schaik CP (1989) The ecology of social relationships amongst female primates. In: Standon V, Foley RA (eds) Comparative socioecology: the behavioural ecology of humans and other mammals. Blackwell Scientific, Oxford, pp 195-218

Watts DP (1988) Environmental influences on mountain gorilla time budgets. Am J Primatol 15:195-211

Watts DP (1989) Infanticide in mountain gorillas - new cases and a reconsideration of the evidence. Ethology 81:1-18

Watts DP (1990a) Ecology of gorillas and its relation to female transfer in mountain gorillas. Int J Primatol 11:21-45

Watts DP (1990b) Mountain gorilla life histories, reproductive competition, and sociosexual behavior and some implications for captive husbandry. Zoo Biol 9:185-200

Watts DP (1992) Social relationships of immigrant and resident female mountain gorillas.1. Male-female relationships. Am J Primatol 28:159-181

Watts DP (1994a) Agonistic relationships between female mountain gorillas (Gorilla gorilla beringei). Behav Ecol Sociobiol 34:347358

Watts DP (1994b) The influence of male mating tactics on habitat use in mountain gorillas (Gorilla gorilla beringei). Primates 35:35-47

Watts DP (1996) Comparative socioecology of gorillas. In: McGrew WC, Marchant LF, Nishida T (eds) Great ape societies. University of Cambridge, Cambridge, pp 16-28

Watts DP (1998) Long term habitat use by mountain gorillas (Gorilla gorilla beringei). 1. consistency, variation, and home range size and stability. Int J Primat 19:651-680

Watts DP (2000) Causes and consequences of variation in male mountain gorilla life histories and group membership. In: Kappeler PM (ed) Primate males. Cambridge University Press, Cambridge, pp 169-180

Weber B, Vedder A (1983) Population dynamics of the Virunga gorillas: 1959-1978. Biol Conserv 26:341-366

Wrangham RW (1980) An ecological model of female-bonded primate groups. Behaviour 75:262-300 